\title{
Interests and attitudes of G.C.E. (A/L) physical science stream students on university education in STEM: A case study in Sri Lanka
}

\author{
Ashan Induranga 1, Kaveendra Maduwantha 1, Buddhika Sampath 1, Neranga Hettiwatta 1, Vimukthi \\ Vithanage 1, Hasarinda Kariyawasam 1, Amalka Indupama 1, Chathudina J Liyanage 2 and Kaveenga \\ Koswattage ${ }^{1, *}$ \\ 1 Department of Engineering Technology, Faculty of Technology, Sabaragamuwa University of Sri Lanka.
2 Department of Food Science and Technology, Faculty of Applied Sciences, Sabaragamuwa University of Sri Lanka.
}

Global Journal of Engineering and Technology Advances, 2022, 10(01), 033-038

Publication history: Received on 01 December 2021; revised on 25 December 2021; accepted on 29 December 2021

Article DOI: https://doi.org/10.30574/gjeta.2022.10.1.0179

\begin{abstract}
Sri Lanka has a free education system that gives access to higher education opportunities through the G.C.E. (Advanced Level) examination to a limited number of students. Students can choose their preferred university course if they have fulfilled the required minimum results for university admission. This paper discusses the general interests and attitudes of a sample of physical science stream students towards university education in STEM as a case study in Sri Lanka. The study has investigated several perspectives of the selected sample of G. C. E. (A/L) students through an online survey that includes questions regarding students' attitudes and perceptions on university education and different STEMrelated undergraduate courses. The study has covered several schools of three provinces in Sri Lanka, and some of the investigated results are discussed with respect to the provinces. The results revealed career prospects, the academic quality of the undergraduate courses and the reputation of the university as the most influencing factors for undergraduate course selection in STEM disciplines, while engineering-related undergraduate courses were the most preferred ones among the students. The study results can be an asset to further studies since this topic has been rarely explored in the Sri Lankan higher education context.
\end{abstract}

Keywords: STEM subjects; Higher education; G.C.E. (A/L); Sri Lanka: Student preference

\section{Introduction}

Sri Lanka is one of the few countries that provides free education from grade one to university. A student usually starts kindergarten at the age of five and concludes the primary and secondary education at the age of 16 by a selective language (i.e., Sinhala, Tamil and English). At the age of 16, a student usually sits for the General Certificate of Education (Ordinary Level) [(G.C.E. (O/L)] examination. Afterwards, they must select a stream for the highly competitive General Certificate of Education (Advanced Level) [(G.C.E. (A/L)] examination where they must complete two years of mandatory school education in the selected stream to be eligible to sit for the examination as a first-attempt candidate. Based on the results of G.C.E. (A/L) examination as well as the individual preferences, students can pursue higher education in universities or can select vocational and technical based education. Arts and humanities, commerce and management, biosciences (including medical disciplines, agriculture, biology and related courses), physical sciences (engineering, chemistry, physics, mathematics and related disciplines) or technology (biosystems, engineering or computer technology) are the main study streams available in public universities. For the last five years, more than 250,000 students have taken the G.C.E. (A/L) examination annually. Around $70 \%$ of them get qualified for university entrance. However, only about $20 \%$ of them are selected to 15 state-owned universities [1,2]. This implies the intense

\footnotetext{
* Corresponding author: Kaveenga Koswattage
}

Department of Engineering Technology, Faculty of Technology, Sabaragamuwa University of Sri Lanka.

Copyright $@ 2022$ Author(s) retain the copyright of this article. This article is published under the terms of the Creative Commons Attribution Liscense 4.0. 
competitiveness in GCE A/L as well the requirement of alternative methods of enabling the students to pursue higher education. Government authorities in Sri Lanka have worked out to expand existing university facilities and establish new faculties to allocate more students to join a state university, particularly in the STEM disciplines. For example, Sabaragamuwa University of Sri Lanka recently established a faculty of medicine and a faculty of technology. In Sri Lanka only $3 \%$ of qualified female candidates and $12 \%$ males are reported to select a STEM first degree. As a comparison, in OECD countries these values are $13 \%$ and $39 \%$, respectively $[3,1]$. STEM education is often promoted in many countries with the expectation of catering social and personal well-being, inclusive growth and sustainable development through innovation and creativity [4]. Thus, STEM education has been discussed and studied globally based on the perception of students and teachers, demographics, and learning methods [5-10]. A thorough analysis of the literature of such case studies has been critical to structure the current study.

\section{Literature review}

Globally, several kinds of studies have been carried out to identify the school students' preference towards higher education in engineering. However, most of these studies focused on engineering and STEM fields in general. Balçın and Ergün studied a group of secondary school students' perceptions in Turkey on engineers and engineering using a questionnaire [11]. Their study categorized the results gender-wise, and most of the male students preferred to select engineering as a career while only $38.46 \%$ of females preferred to select an engineering career. According to students' perception of engineers, construction workers, repairers or managers were the main roles. Owing to this reason, female students were reluctant to select engineering as a future career. Kizllay et al. conducted a study with 2129 students from five public schools in Turkey focusing on students' preferences, mainly considering STEM-related career paths [12]. The study also focused on students' preferred universities for their favorite courses. The data analysis was performed by categorizing them according to grade level in school and gender of the students.

Another study highlighting female students in the public schools of the United States revealed the importance of students' context on constructing their science identity [13]. The study was conducted considering the race and ethnicity of the students. The science identity of the students was studied from the perspective of themselves, their families, friends and teachers. Sáinz and Müller conducted somewhat similar study considering family and gender influences on the Spanish students' aspirations and values in STEM fields [10]. The researchers used an open-ended question categorized according to the fields of knowledge recognized by the Spanish Ministry of Education. A similar research hypothesis that can be identified in these kinds of research is the gender gap in career choice [5,6]. It can be identified that the effect of gender is still a very important factor even in developed countries. However, even in developed countries like Canada, most of the students have limited STEM career knowledge with respect to subject requirements and with respect to what sort of activities such careers involve [14].

Besides the career or degree choice of the school students, students also focus on the selection of the university. With the increment of the facilities of academics worldwide and with the introduction of private universities, it can be observed that students' factors on selecting the universities become much complex [15]. Budur et al. conducted a study to identify the students' perceptions of university selection in the Kurdistan Region of Iraq [16]. It was revealed that majority of the students select a university considering the reputation of the university, scientific activities and satisfaction of the current students. The importance of university reputation is also justified in the study conducted by Islam and Shoron, based in Bangladesh [7]. However, the study focused on 153 undergraduate students in two private universities. In another similar kind of study conducted with a total of 509 students in three public high schools in Ho Chi Minh City, Vietnam, university reputation was the least considerable factor while job prospects after graduation, quality of teaching and expertise of teaching staff were the main factors [17].

Even though such case studies based in many countries are readily available, locally developed studies are very limited, at least in the case of university selection [18]. Therefore, the current study intends to evaluate the perception of physical science stream students on higher education in the corresponding stream.

\section{Material and methods}

The main objective of the study was to identify the eagerness of the students about the university education in STEM subjects from their personal attitudes, interests and preferences. An online questionnaire was used to gather data from physical science stream students in three provinces of Sri Lanka, namely, Sabaragamuwa, Southern and Western. The questionnaire was shared among the grade 12 and 13 students in the physical science stream who are studying the subjects of combined mathematics, physics, chemistry or information and communication technology. The questionnaire consists of fifteen survey questions and five optional demographic questions. The questionnaire response 
was restricted to only one per student. The questionnaire was categorized into several sections to obtain an insight on the preference of the STEM fields and the factors considered for university selection. The results were compared province wise. Statistical analysis of data was carried out by Microsoft Excel, Office 365 application suite, (Microsoft Corporation, U.S.A.) and Minitab Version 19 (Minitab Inc, U.S.A.).

\section{Results and discussion}

The sample characteristics of the study are outlined in Table 1 and Table 2 . The most important finding of the study is that the majority of the students expecting to earn an undergraduate degree are willing to attend public universities, while Sabaragamuwa province stands out with $98 \%$ compared to $83 \%$ and $88 \%$ for Southern and Western provinces, respectively.

Table 1 Sample distribution of selected students: province wise

\begin{tabular}{|l|c|c|c|c|}
\hline Province & Sabaragamuwa & Southern & Western & Total \\
\hline Frequency & 66 & 49 & 54 & 169 \\
\hline Percent & 39.05 & 28.99 & 31.95 & \\
\hline
\end{tabular}

The socio-economic statistics of the provinces can be considered for interpreting some findings. According to the most recent Socio-Economic Data of Sri Lanka published by the Central Bank of Sri Lanka, Sabaragamuwa Province has the lowest mean income per household among the three provinces selected for the study. From this, we can infer that private education is not affordable for them with the majority of students in the province expecting free public education. Further, by the responses to the question 'Do you think the current opportunities provided by Government Universities for Engineering education is sufficient?' (Insufficient - Sabaragamuwa/86.4\%, Southern/85.7\% and Western/81.5\%), students' perception of the opportunities for studying engineering in state universities can be identified.

Table 2 Sample distribution of selected students: G.C.E. (A/L) sitting year

\begin{tabular}{|l|c|c|c|}
\hline Year & $\mathbf{2 0 2 1}$ & $\mathbf{2 0 2 2}$ & Total \\
\hline Frequency & 64 & 105 & 169 \\
\hline Percent & 37.87 & 62.13 & \\
\hline
\end{tabular}

It is obvious that the majority ( $>75 \%$ ) of the physical science stream students expect to pursue an engineering course after their secondary education. Further, this pattern is preserved among all three provinces. A possible cause for this outcome is the existence of a common belief regarding a privileged and secured job market in engineering. Surprisingly, the choice of selecting an engineering course is not much affected by the availability of a good job market (26.09\%). Instead, the choice is largely based on the personal preferences on a career path (68.94\%).

As outlined in Table 3, based on responses to the question 'If you wish to seek Engineering education, what is your preferred stream or field of specialization?', it is revealed that the current expectation for specializing in an engineering stream in computer science is the most popular. Conventional civil, mechanical and electrical and electronics engineering courses are together responsible for more than half of the responses. This may suggest a possible lack of information on those courses offered by state universities and requires a further investigation for confirmation.

Considering the factors that could influence the selection of a university over the sample categories, it is identified that they follow the same pattern, as indicated in Figure 1. The responses were recorded as a 5 - point Likert-type scale and averaged. All the factors were equally considered except for the public opinion and opinion of classmates (region with dashed circle in Figure 1). Both are considerably averaged in the middle of a scale of 1 to 5. This is almost consistent with factors mentioned except campus visits in similar studies conducted by Kusumawathi (2003) and Islam and Shoron (2019) based in Indonesia and Bangladesh respectively [7, 19]. It is worthy of noting that the decision making is biased on many opinions, and a public event like a university open day can contribute directly to spread the details of courses and degrees offered by each university among the public $[20,21]$. 
Table 3 Choice of specialization in engineering strea

\begin{tabular}{|l|c|c|}
\hline Engineering Field & Frequency & Percent \\
\hline Chemical Engineering & 13 & 8.33 \\
\hline Civil Engineering & 35 & 22.44 \\
\hline Computer Science Engineering & 50 & 32.05 \\
\hline Electrical and Electronics Engineering & 20 & 12.82 \\
\hline Mechanical Engineering & 18 & 11.54 \\
\hline Other & 15 & 9.62 \\
\hline Production and Process Engineering & 5 & 3.21 \\
\hline Total & 156 & \\
\hline
\end{tabular}

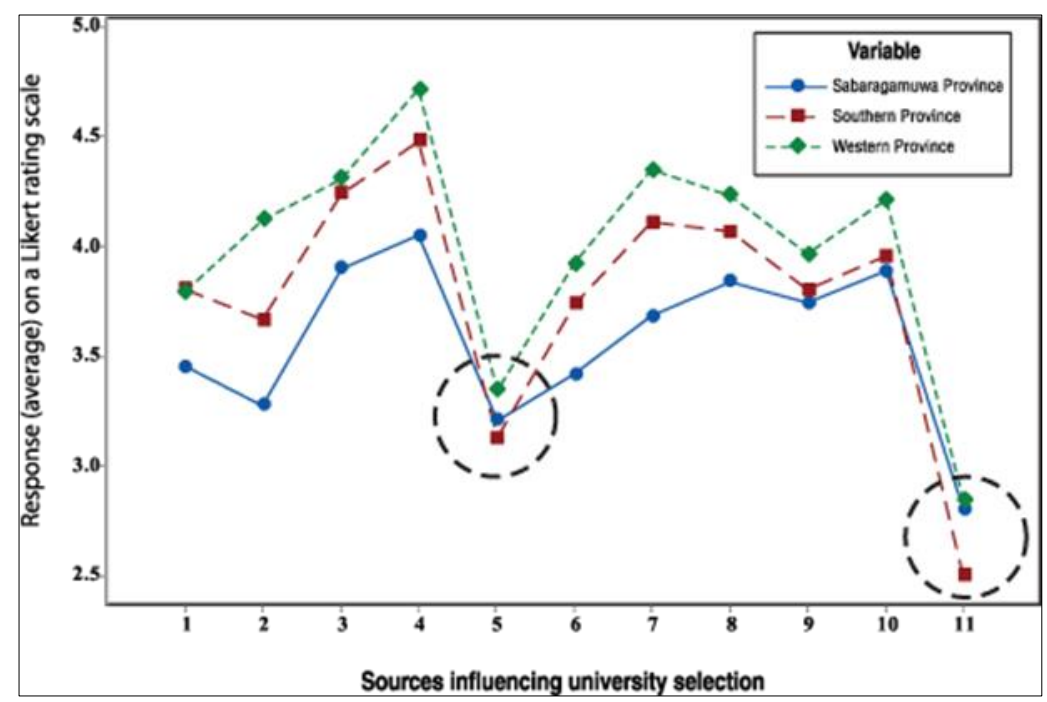

Figure 1 Responses to the question 'How much do you consider the information from a certain source when selecting a university?' (1 - The information available on university web sites 2 -Information given Program Prospectuses and the contents 3- The reputation of the Faculty and University 4 - Academic quality and research strength of the university 5 - Popular public opinion 6 - What current students of the university say 7 - What graduates of the university say 8 What your teachers at school say 9 - What your tuition masters say 10 - What your parents say 11 - What your classmates say)

\section{Conclusion}

Based on the findings of the current study we can conclude the following on STEM education perceptions of G.C.E. (A/L) students in the physical science stream.

- Future careers of physical science students are expected to be oriented around engineering education.

- The study group strongly believes that the number of current public university opportunities should be increased.

- University selection is determined at most by the factors such as academic quality and the reputation of the universities. The least considered factors are public opinion and opinion from the peers.

- The study group considered computer science engineering and conventional engineering as the most valued courses.

Based on the conclusions we recommend, 
- To disseminate the information and facts on the importance of STEM education among G.C.E. (A/L) students.

- To motivate students at the school level to pursue STEM related courses considering the increasing job availability both locally and globally.

- To conduct University Public Open days, and seminars for G.C.E. (A/L) teachers as they would serve as better methods to convey information directly to the prospective university entrants about courses that are not popular among the public but highly valued in industry.

- To prepare a national policy of achieving STEM enrolment rates comparable with OECD countries. This will provide the necessary educational requirements for the future careers of students in the STEM courses and in return the country will benefit from a globally recognized skilled work-force.

(Note - The study was carried out with the intention of gathering opinions on the establishment of a new Faculty of Engineering at the Sabaragamuwa University of Sri Lanka)

\section{Compliance with ethical standards}

\section{Acknowledgments}

The authors appreciate the support given by the school students and teachers for this successful survey.

\section{Disclosure of conflict of interest}

The authors declared no potential conflicts of interest concerning the research, authorship, and/or publication of this article.

\section{References}

[1] Sri Lanka University Statistics. 2020; 190.

[2] Statistical Pocket Book-2020 Sri Lanka. (2020). Department of Census \& Statistics.

[3] OECD (2021). Education at a Glance: OECD Indicators. 2021.

[4] UNESCO International Symposium and Policy Forum. Cracking the code: Girls' education in STEM. 2017.

[5] Buser T, Peter N, Wolter SC. Gender, Competitiveness, and Study Choices in High School: Evidence from Switzerland. American Economic Review. 2017; 107(5): 125-130.

[6] Card D, Payne AA. High school choices and the gender gap in STEM. Economic Inquiry. 2021; 59(1): 9-28.

[7] Islam MdA, Shoron NH. Factors Influencing Students' Decision Making in Selecting University in Bangladesh. Advanced Journal of Social Science. 2019; 6(1), 17-25.

[8] Nguyen TPL, Nguyen TH, Tran TK. STEM Education in Secondary Schools: Teachers' Perspective towards Sustainable Development. Sustainability. 2020; 12(21): 8865.

[9] Nifo A. The rule of law and educational choices: Evidence from Italian regions. Regional Studies. 2017; 16.

[10] Sáinz M, and Müller J. Gender and family influences on Spanish students' aspirations and values in stem fields. International Journal of Science Education. 2018; 40(2): 188-203.

[11] Balçın MD, Ergün A. Secondary School Students' Perceptions and Attitudes about Scientists. 2018.

[12] Kizilay E, Yamak H, Kavak N. High School Students that Consider Choosing Science, Technology, Engineering, and Mathematics (STEM) Fields for their University Education. Science Education International. 2019; 30(1).

[13] Vincent-Ruz P, Schunn CD. The nature of science identity and its role as the driver of student choices. International Journal of STEM Education. 2018; 5(1): 48.

[14] Blotnicky KA, Franz-Odendaal T, French F, Joy P. A study of the correlation between STEM career knowledge, mathematics self-efficacy, career interests, and career activities on the likelihood of pursuing a STEM career among middle school students. International Journal of STEM Education. 2018; 5(1): 22.

[15] Dowling-Hetherington L. Transnational Higher Education and the Factors Influencing Student Decision-Making: The Experience of an Irish University. Journal of Studies in International Education. 2020; 24(3): 291-313. 
[16] Budur T, Rashid CA, and Poturak. Students Perceptions on University Selection, Decision Making Process: A Case Study in Kurdistan Region of Iraq. International Journal of Social Sciences \& Educational Studies. 2018; 5(1): 133144 .

[17] Robinson LJ, Dobele AR. Understanding high school student's use of choice factors and word-of-mouth information sources in university selection. Studies in Higher Education. 2020; 45(4): 808-818.

[18] Polgampala ASV, Shen H, Huang F. Perceptions on STEM Education in Secondary Schools in Sri Lanka: Trends and Challenges. Imperial Journal of Interdisciplinary Research. 2016; 2(12): 301-306.

[19] Kusumawati A. Students' perceptions of choice criteria in the selection of an Indonesian public university [Doctor of Business Administration Thesis, University of Wollongong]. 2013.

[20] UCAS. 2014.

[21] Wood J. What's a university open day? Complete University Guide. 2021. 